Article

\title{
Study on Business Ecosystem Research Trend Using Network Text Analysis
}

\author{
Matthew Minsuk Shin ${ }^{1}$, Seunghye Jung ${ }^{1}$ and Jin Sung Rha ${ }^{2, *(D)}$ \\ 1 Department of International Trade, College of Social Science, Konkuk University, Seoul 05029, Korea; \\ shinm@konkuk.ac.kr (M.M.S.); wjdtmdgp1005@konkuk.ac.kr (S.J.) \\ 2 School of Business Administration, Dankook University, Yongin 16890, Korea \\ * Correspondence: jinsungrha@dankook.ac.kr; Tel.: +82-31-8005-3417
}

Citation: Shin, M.M.; Jung, S.; Rha, J.S. Study on Business Ecosystem Research Trend Using Network Text Analysis. Sustainability 2021, 13, 10727. https://doi.org/10.3390/ su131910727

Academic Editor: Jose Ramon Saura

Received: 22 August 2021

Accepted: 22 September 2021

Published: 27 September 2021

Publisher's Note: MDPI stays neutra with regard to jurisdictional claims in published maps and institutional affiliations.

Copyright: (c) 2021 by the authors. Licensee MDPI, Basel, Switzerland. This article is an open access article distributed under the terms and conditions of the Creative Commons Attribution (CC BY) license (https:// creativecommons.org/licenses/by/ $4.0 /)$.
Abstract: The management environment is moving into a new phase with the changing global circumstances. The business ecosystem as a management strategy has been studied for the last 30 years since the concept was introduced. The purpose of this study was to analyze the research trend in business ecosystem by using network next analysis and to understand the concept, being one that is still being actively studied. Network text analysis is a commonly used method to analyze research trends by forming networks based on bibliographic data of the articles, namely, keywords. For the analysis, we collected the data and keywords from 340 research papers published in global academic journals related to business ecosystem on the basis of the Scopus database. Through keywords extraction and cleansing, we found that the keywords of "innovation", "sustainability", and "platform" were mentioned most frequently, and the research topics were correlated to each other. Moreover, we conducted degree centrality and betweenness centrality analysis along with clustering analysis by transforming the two-mode network into a one-mode network. Degree centrality involves analyzing the degree to which one keyword links to other keywords, and betweenness centrality shows the mediating effects of a keyword to other keywords. In the centrality analysis results, "innovation", "sustainability", "platform", and "business model" showed the highest degree centrality, and "sustainability", "innovation", "China", and "platform" had the highest betweenness centrality. Then, we classified the clusters of subtopics into five groups. The current study examined accumulated research and suggested a comprehensive understanding of the research trend in business ecosystem by incorporating a method enabling research trend analysis to secure objectivity. This research is expected to help researchers to review the research trend in business ecosystem and identify expandable topics for further studies.

Keywords: business ecosystem; innovation; sustainability; platform; network text analysis

\section{Introduction}

Adapting to rapidly changing environment is the key point of business in this age of globalization. The traditional supply chain concept is becoming no longer adequate in current times. Corporates need strategical transitions to keep up with the changing global circumstances as the border and area of suppliers, customers, distributors, and other actors involved in the business are being expanded [1]. Since Moore [2] introduced the term "business ecosystem", diverse relevant subjects have been studied in the way of incorporating the concept to various fields and systems. The current study analyzes the research trend of business ecosystem that has accumulated over the last 30 years. While related subjects are being studied accordingly with changing management circumstances, a comprehensive approach is still limited. The process of identifying and classifying subtopics studied along with business ecosystem would suggest a new idea to further research as well as review the concept overall. As with the metaphorical connection with biological ecosystem, the business ecosystem means all the connections and interchanges 
between members involved in business. The business ecosystem refers to a distinctive organizational form consisting of members co-evolving their capabilities and aligning themselves with a common interest [1].

To provide a general definition, the current study reviewed articles defining the business ecosystem in the literature review and found out that they commonly conceptualized the business ecosystem into four groups, namely, network, actors' role, innovation, and platform perspectives. Each researcher defined the business ecosystem from different perspectives. While the complexity of the business ecosystem is increasing, the definition is still widely varied [3]. Together with the constantly increasing interest in business ecosystem, the consensus definition and understanding of the concept are essential for both academic and practical usage.

The current study collected academic articles written in English using Scopus, a global academic database platform by Elsevier. A total of 340 relevant articles containing business ecosystem as a keyword were selected. To analyze the research trend, the current study used a method of network text analysis. While most of the previous studies analyzing research trends classified relevant research on the basis of the researcher's subjectivity, the network text analysis examines the keywords extracted from the articles, and the procedures secure the objectivity of study. This study additionally took a step of cleansing the keywords referring to the same meaning in order to prevent classifying them as different words and then built the keyword network and world cloud. The network enables the identification of the most frequently studied topics within the business ecosystem, and the word cloud is an intuitive schematized diagram of the keywords. The network at this point means a two-mode network composed of articles and keywords. In a two-mode network, the keywords and articles are linked to each other, not a keyword to other keywords. Thus, the current study transformed the two-mode network to a one-mode network in order to analyze the centrality between keywords. The centrality analysis examined the degree to which a keyword links to other keywords and also the mediating effect. After determining the relationship between keywords, this study classified the clusters of subtopics into five groups. The analysis is presented in the Results section of this paper.

\section{Literature Review}

\subsection{Definition of Business Ecosystem}

The business model is the architectural implementation of the business strategy. The organizational goals become a reality when the strategy and the business model are aligned [4]. The business model reflects how a business creates value, along with the revenue, costs, and profits associated with the business [5]. Designing a viable business model has become complex in today's global business environment with globalized stakeholders, value creation, resource, channels, cost structure, and revenue streams [6]. The traditional business models show limitations in reflecting today's rapidly changing circumstances; thus, necessity rises for concurrent firms of an alternative business model [7]. As the alternative, the notion of business ecosystem is being widely adapted and studied.

Business ecosystem is a descriptive term that generally explains today's interconnected business [8]. Simply put, business ecosystem means the network of organizations participating in a common business. Since the biological ecosystem is a network of various individual organisms that constitute a system, the biological ecosystem and business ecosystem share metaphorical connection. Both ecosystems consist of inhabitants joined by diverse mutual relationships [9]. Iansiti and Levien [10] pointed out that the business ecosystem has three distinctive characteristics: (1) innovation, (2) competition for members, and (3) intelligent actors. The members of a business ecosystem engage in innovative activities for the ecosystem-wide growth. Moreover, the ecosystem is in constant competition against other business ecosystems to attract attractive members. Finally, the members of business ecosystem are able to make autonomous decisions [10]. The business ecosystem differs from the traditional supply chain concept as the focal firm in a supply chain has general control over the whole business process, whereas the business ecosystem is rather 
modular [11]. Further, in a dynamic business ecosystem, as the boundaries between the competitor and partner become blurred, the ecosystem enables the organizations to expand the scope and area [12]. In terms of business expansion, the interactions with diverse multidisciplinary businesses, primary industry, adjacent industry, or even unexpected industry, could be available [13]. Due to the characteristics mentioned above, it is being widely used in industry and studied increasingly through interdisciplinary research.

\subsection{Previous Research}

As an overall review of studies containing a definition of business ecosystem, the current study examined business ecosystem definitions and categorized the definitions into four groups: (1) network, (2) actors' role, (3) innovation, and (4) platform. Reviewed studies categorized into the four categories are organized in Table 1. (1) Network refers to the connection and interaction between actors participated in the ecosystem. If the (1) network focuses on the overall connection of the ecosystem, (2) the actors' role focuses on the importance of each actors' operation on the network. (3) Innovation regards the business ecosystem as a part of innovation in the corporate environment and emphasizes that it accompanies technological innovation. The studies categorized as (4) platform additionally emphasize the role of service, tools, or technologies to enhance the performance of the business ecosystem $[1,11,14]$.

Table 1. Overview on definitions of business ecosystem.

\begin{tabular}{ccccc}
\hline Research & Network & Actors' Role & Innovation & Platform \\
\hline Moore (1996) & $\mathrm{V}$ & & & \\
Iansiti and Levien (2004) & $\mathrm{V}$ & $\mathrm{V}$ & $\mathrm{V}$ & $\mathrm{V}$ \\
Den Hartigh and van Asseldonk (2004) & $\mathrm{V}$ & & $\mathrm{V}$ & $\mathrm{V}$ \\
Peltoniemi and Vuori (2004) & $\mathrm{V}$ & & & \\
Quaadgras (2005) & $\mathrm{V}$ & & $\mathrm{V}$ & $\mathrm{V}$ \\
Li (2009) & $\mathrm{V}$ & $\mathrm{V}$ & $\mathrm{V}$ & $\mathrm{V}$ \\
Muegge (2013) & $\mathrm{V}$ & & $\mathrm{V}$ & $\mathrm{V}$ \\
Tsujimoto et al. (2018) & $\mathrm{V}$ & & $\mathrm{V}$ & \\
Jacobides et al. (2018) & $\mathrm{V}$ & $\mathrm{V}$ & $\mathrm{V}$ & $\mathrm{V}$ \\
\hline
\end{tabular}

Moore first introduced the business ecosystem framework in 1993 and defined it as an economic community supported by a foundation of interacting organizations and individuals, with the organisms of the business worlds including customers, suppliers, lead producers, competitors, and other stakeholders [15].

Iansiti and Levien [14] defined the business ecosystem as loose networks of suppliers, distributors, outsourcing firms, makers of related products or services, technology providers, and a host of other organizations that affect and are affected by the creation and delivery of a company's own offerings. In the study, they introduced Wal-Mart and Microsoft as examples that created platforms as additional actors of the business ecosystem. The platform refers to the information service and system that enhances the performance of the business ecosystem.

Den Hartigh and van Asseldonk [16] constructed a study examining the relationship between network structure, firm strategy, and the pattern of innovation diffusion. They defined the business ecosystem as a network of actors around a core technology who depend on each other for their success and survival. In this study, the business ecosystem is the network of firms organized around a technological platform.

Peltoniemi and Vuori [8] defined the business ecosystem as a dynamic structure that consists of an interconnected population of organization. Their study suggests that the business ecosystem is a complex system consisting of self-organization, emergence, coevolution, and adaptation. The business ecosystem is a process in which the participants of the business connect mutually without focal leading organization. 
Quaadgras [17] constructed a case study of RFID (radio-frequency identification) business ecosystem and defined the business ecosystem as a set of complex products and services made by multiple firms in which no firm is dominant. The technology, RFID, is supported by the business ecosystem consisting of firms trying to develop a platform. In this study, the platform is a developed concept from the business ecosystem.

Li [18] constructed a case study based on Cisco's strategy. In this study, the ecosystem is defined as "linking customers, employees, manufacturers, and other supply chain partners". This study focuses on the partnership and symbiosis. Business ecosystem is comprises symbiosis, platform, and co-evolution, which means it enables the transfer of the business strategy from a single co-work to synergic and systematic cooperation, from product competition to platform competition, from single-growth to co-evolution.

Muegge [1] defined the business ecosystem as "a field of economic actors whose individual business activities, anchored around a platform, share in some large measure the outcome of the whole ecosystem". Muegge [1] provides three levels of interconnected organizations: platform, community, and business ecosystem, that is, he separated the three levels as different business model forms.

In the study of Tsujimoto et al. [19], the business ecosystem is to provide a product/service system, an historically self-organized or managerially designed multilayer social network consisting of actors that have different attributes, decision principles, and beliefs. This study classified four major research streams of ecosystem into industrial ecology, business ecosystem, platform management and multi-actor network in the field of technology and innovation.

Jacobides et al. [11] defined the business ecosystem as a set of actors with varying degrees of multi-lateral, non-generic complementarities that are not fully hierarchically controlled. This study examined the emergence of the business ecosystem concept and distinctive characteristics of business ecosystem compared to other organizational forms.

According to Table 1, the studies commonly define business ecosystem on the basis of interactions between actors, yet each study additionally emphasizes different aspects. Even though the definitions share perspectives in terms of network, actors' role, innovation, and platform, they are widely varied. Thus, they require consensus definitions for further academic and practical usage.

\subsection{Research Objective}

Ritter and Gemünden [20] point out that, in the network economy, the firm's competitiveness does not only depend on its internal competence but also on its ability to interact with its environment. Research on business strategy on various dimensions makes for a better understanding of continuous interaction and behavior of interconnected organizations [21]. However, despite of the recent 30 years of studies, the understanding of business ecosystem is limited because of the definition of the concept is ambiguous. Thus, this study suggests the necessity of agreed definitions by analyzing the studies related to business ecosystem in the last 30 years that have been published in top 30 management journals.

\section{Method: Network Text Analysis}

Network text analysis is commonly used to analyze recent research trends. While most previous studies analyzing the research trends classified and analyzed relevant research articles on the basis of the researcher's subjectivity, network text analysis quantitatively analyzes the research trends by forming networks on the basis of bibliographic data [22]. Network text analysis includes text mining and text analysis. Text mining is performed to explore meaningful information from textual data, and network analysis investigates the influence of each node and network structure. Networks are composed of nodes and arcs. In network text analysis, nodes can be the keywords, authors, and articles, and arcs are used to form the connections among nodes to show keywords, authors, co-citations, and citation networks. Network text analysis can be used to analyze major research topics, research groups, and articles in the field, while also presenting future research topics. 
Research trend analysis using network text analysis is generally conducted in the following order. First, it is necessary to search the research articles that are to be analyzed. This study used the academic database Scopus, which includes the world's largest number of journals, to search articles. Scopus is a global academic database platform owned by Elsevier and used by many studies to analyze research trends with network text analysis [23-25]. Scopus offers a correlation analysis of relevant articles by entering search words. In this study, "business ecosystem" was used as the search word. All types of academic data can be searched on Scopus, but this study limited the type to academic articles, and the subject to "business" and "social science". Only articles written in English were selected to facilitate the analysis. The bibliographic data of major research articles were downloaded onto Excel for analysis.

Second, a two-mode network was built with keywords and research articles as nodes on the basis of the key bibliographic data of articles on business ecosystem. The keywords of each article can be extracted on the basis of the frequency of abstracts or titles, but in this case, the intentions of researchers may be distorted. Therefore, this study first used the keywords presented by the researchers in their articles as they were. Since there are cases in which different terms are used to indicate the same meaning, three researchers in the relevant field were consulted to come up with final keywords. It is difficult to analyze network centrality and clusters immediately in a two-mode network. Through a two-mode network, it is possible to examine whether research articles on business ecosystems are covering similar or different research topics within one big frame. Since this study focused on keyword network, the two-mode network comprised two dimensions, namely, "research articles" and "keywords".

Third, the two-mode network was transformed into the one-mode network. It is difficult to conduct network analysis focusing on the connection among keywords with just the two-mode network. Therefore, this study transformed the two-mode network to the one-mode network composed only of keyword nodes. Cosine similarity was used as the algorithm for transformation. Keywords were limited to only those appearing at least twice, and the cut off value of cosine similarity was 0.2 . The algorithm for transformation was based on co-occurrence of keywords. The following example helps in understanding cooccurrence. Suppose that article A presented the keywords a, b, and c; article B presented the keywords b, c, and d; and article $C$ presented the keywords b, c, and e. The keywords presented in the three articles show that the keywords $b$ and c co-occurred three times and are strongly correlated to one another. In a keyword network, keywords b and c nodes are likely to be linked by arcs. Here, the network comprised of links among the articles $(\mathrm{A}, \mathrm{B}, \mathrm{C})$ and presented keywords $(\mathrm{a}, \mathrm{b}, \mathrm{c}, \mathrm{d}, \mathrm{e})$ is the two-mode network, which can be transformed to one-mode by using only the keywords as nodes.

Fourth, the characteristics of the one-mode network composed only of keywords were analyzed. This study conducted centrality and clustering analysis. Centrality analysis helps to determine various research topics on business ecosystems and analyze which subtopics have been actively studied. Centrality analysis is classified into degree centrality and betweenness centrality analysis. Topics with high degree centrality were the most actively studied topics, and those with high betweenness centrality can be classified as expandable topics that connect subtopics. Cluster analysis helps in the analysis of subtopics on business ecosystems by grouping them. This study conducted a cluster analysis of research topics on the basis of the method by Blondel. Figure 1 explains the overall procedures of network text analysis. 
1. Search articles using an academic database

- Use Scopus as an academic database

- Use 'business ecosystem' as the search word

- Limit the subject of analysis to articles published in academic journals

2. Build a two-mode network with research articles and keywords

- Use keywords presented by the researchers in the articles

- Consult three experts in the relevant field for keyword cleansing

3. Build a one-mode network comprised only of keyword nodes

- When transforming from two-mode to one-mode, consider only keywords that appeared at least twice

- Use cosine similarity as the transformation algorithm and set the cut off value at 0.2

4. Conduct keyword network analysis

- Conduct analysis of degree centrality and betweenness centrality to analyze the most actively studied subtopics and highly expandable research topics

- Identify the groups of research topics through cluster analysis and analyze the research trends

Figure 1. Procedures of network text analysis.

\section{Results}

\subsection{Articles Selected for Analysis}

This study used the academic database of Scopus to search research articles in the field of business ecosystems. Scopus is an academic data platform developed by the publishing company Elsevier (Amsterdam, The Netherlands) in 2004 that includes the largest number of journals in the world, offering the most effective article search through related search function. Therefore, many studies analyzing research trends use Scopus as a database. "Business ecosystem" was searched as the search word on the search engine, and only articles published by journals written in English were selected, excluding conference proceedings and business magazines. A total of 340 articles were ultimately selected for research trend analysis. Figure 2 shows the number of articles published in Scopus indexed journals on the topic of business ecosystems by year. Studies on business ecosystems have been constantly increasing since 2005. This implies that researchers have more and more interest in business ecosystems due to globalization, increased complexity, and digitalization of business environments. Table 2 shows the rate of journals publishing articles on business ecosystems, revealing that a variety of journals have published articles on business ecosystems.

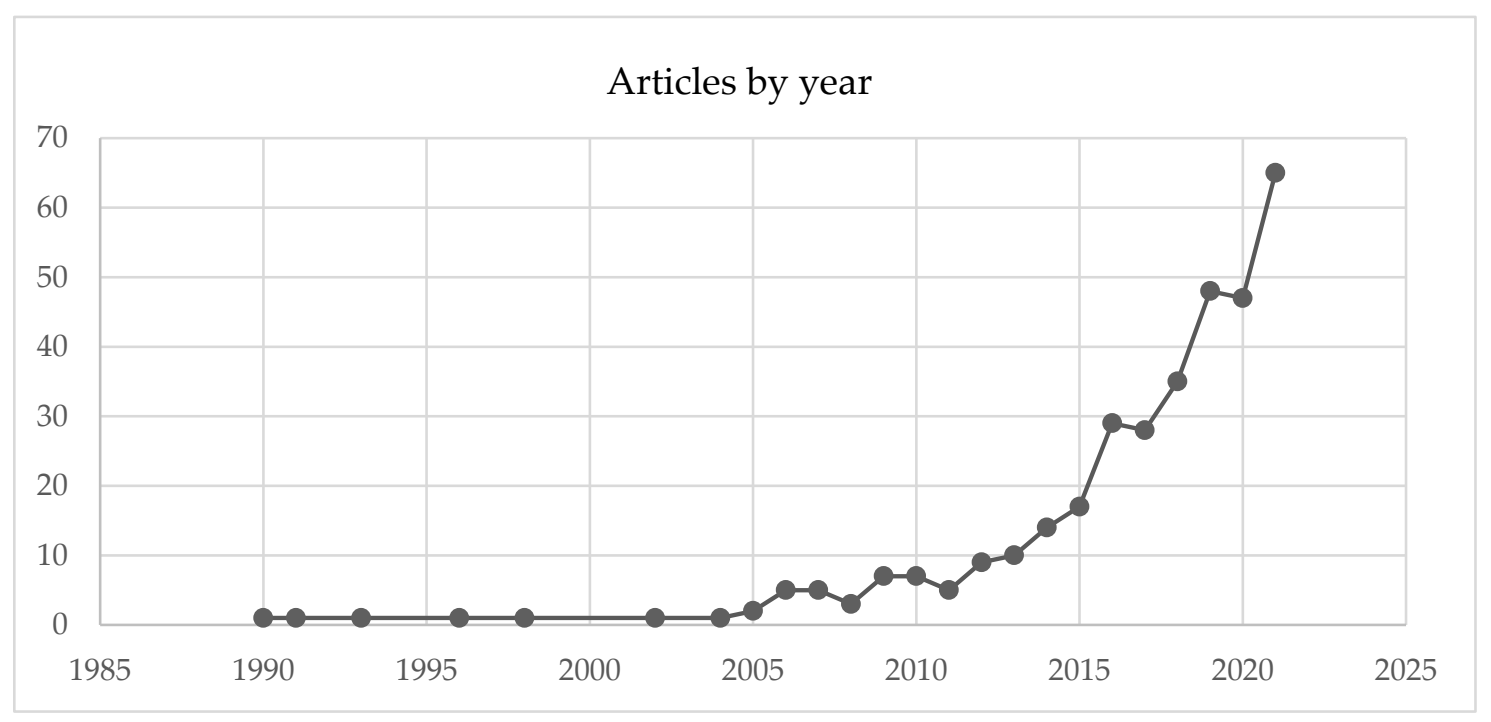

Figure 2. Articles published by year. 
Table 2. Journals publishing articles on business ecosystems.

\begin{tabular}{rc} 
Journal & Number of Articles \\
\hline Sustainability & 15 \\
Journal of Cleaner Production & 11 \\
Strategy and Leadership & 8 \\
Strategic Management Journal & 6 \\
Strategy and Leadership & 6 \\
International Journal of Technology Management & 6 \\
Telecommunications Policy & 6 \\
Journal of International Management & 5 \\
Technology Analysis and Strategic Management & 4 \\
Technovation & 4 \\
Asian Business and Management & 4 \\
Business Horizons & 3 \\
Electronic Markets & 3 \\
European Journal of Innovation Management & 3 \\
Industrial Management and Data Systems & 3 \\
Industry and Innovation & 3 \\
Innovation: Management, Policy and Practice & 3 \\
International Journal of Innovation and Learning & 3 \\
International Journal of Innovation and Technology Management & 3 \\
International Journal of Knowledge-Based Development & 3 \\
International Journal of Production Economics & 3 \\
Journal of Business Ethics & 3 \\
Journal of International Business Studies & 3 \\
Organization Science & 3 \\
Research Policy & 3 \\
Research Technology Management & 3 \\
\hline
\end{tabular}

\subsection{Network Building}

Keywords presented by researchers were first extracted to build a keyword network. When it was difficult to check the keywords of research articles on Scopus, keywords were added by individually searching the relevant articles. For articles in which the researchers have not presented the keywords, the main words were excerpted from the titles and extracted as keywords. The keywords were cleansed after extraction. This was because researchers sometimes use different keywords that indicate the same thing. For instance, some researchers use the word "co-creation", while others refer to it as "co creation". These keywords have the same meaning, but without data cleansing, they may be classified as different keywords. Three researchers in strategic management were consulted for keyword cleansing. Moreover, since "business ecosystem" was used as the search word, the major keywords were "business ecosystem" or "ecosystem" in many cases. Thus, they could not be regarded as a meaningful keyword in building a keyword network, and therefore they were excluded from the results of analysis. Table 3 shows the frequency of keywords presented in 340 articles. A word cloud was created, as shown in Figure 3, according to the frequency. The words in larger font size indicate that they were keywords presented in many articles. The most frequently mentioned keywords in articles on business ecosystems were "innovation", "sustainability", "platform", "network", and "digital". Through keywords extraction and cleansing, it appeared that the keywords related to business model, innovation, and sustainability were mentioned most frequently. 
Table 3. Keyword frequency.

\begin{tabular}{cccc}
\hline Keywords & Degree & Keywords & Degree \\
\hline Innovation & 49 & Business model innovation & 7 \\
Sustainability & 28 & Start up & 7 \\
Platform & 24 & Co-evolution & 6 \\
Network & 21 & Coopetition & 6 \\
Digital & 20 & Dynamic capabilities & 6 \\
Entrepreneurship & 19 & Business models & 6 \\
Knowledge & 18 & Knowledge management & 5 \\
Business model & 17 & Smart tourism & 5 \\
SMEs & 16 & Learning & 4 \\
Case study & 14 & Digital transformation & 4 \\
Value chain & 13 & Sustainable & 4 \\
Strategy & 12 & Industry 4.0 & 4 \\
Open innovation & 12 & Platform strategy & 4 \\
Supply chain & 11 & Lifecycle & 4 \\
China & 10 & Leadership & 4 \\
Value creation & 9 & Business strategy & 4 \\
Collaboration & 9 & Design & 4 \\
Service & 8 & Strategic management & 4 \\
Internet of things & 8 & & \\
\hline
\end{tabular}

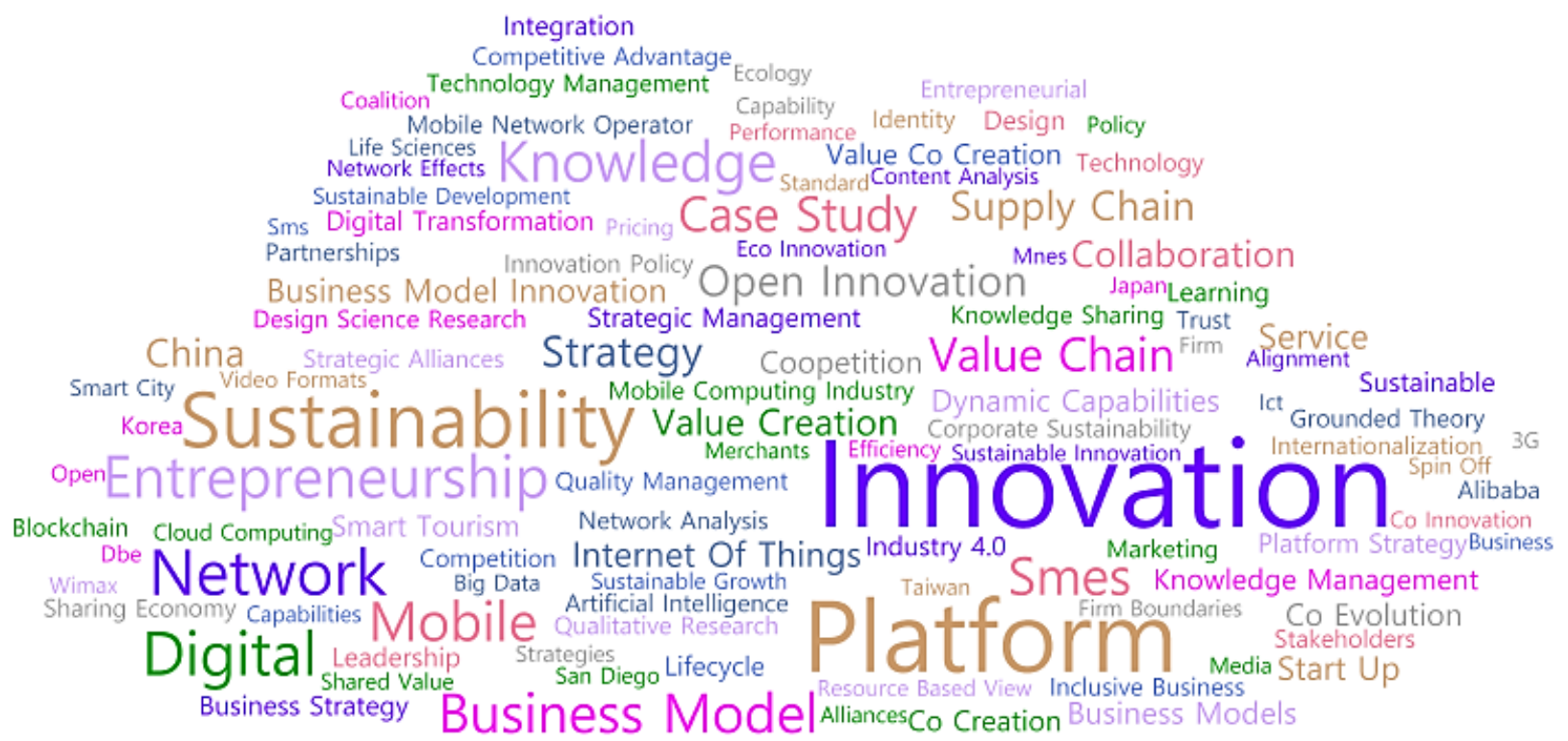

Figure 3. Word cloud.

After keyword cleansing, a two-mode network composed of research article and keyword nodes can be built. In a two-mode network, keywords are linked only to article nodes, and articles are also linked only to keyword nodes. Since keywords are not directly linked to one another, it is impossible to directly analyze keyword nodes in this state. Figure 4 shows the two-mode network of articles and keywords. The network is separated by some research articles, but most form one giant network. This indicates that, except for a few articles on business ecosystems, most include research topics that are correlated to one another. 

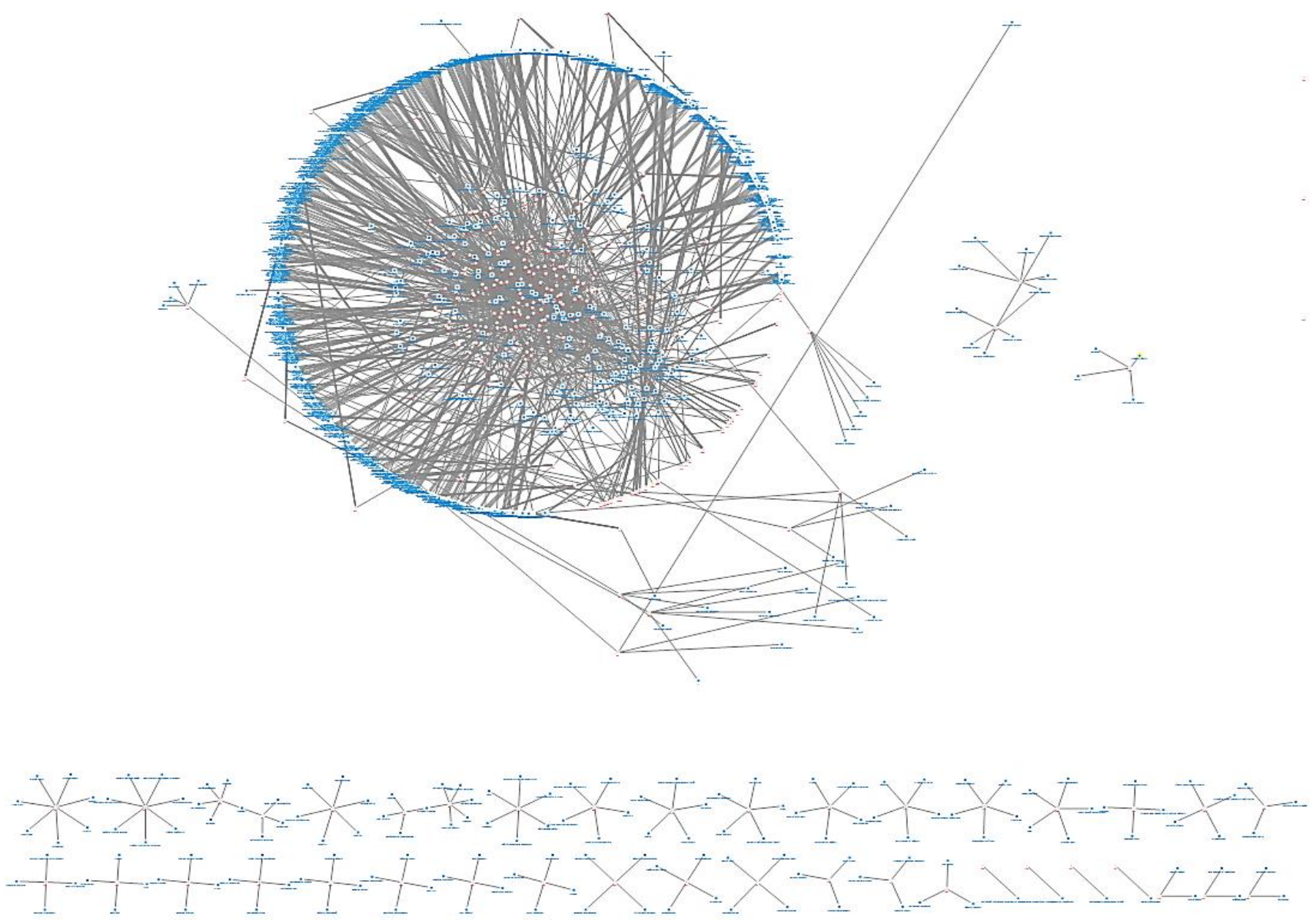

Figure 4. Two-mode network comprising article and keyword nodes.

Cosine similarity is calculated and used to transform the two-mode network comprising articles and keywords into the one-mode network composed only of keyword nodes. Cosine similarity can be calculated as shown in Equation (1). This study used only the keywords that appeared at least twice in 340 articles to build the one-mode network. The cut off value of cosine similarity was 0.2 . The one-mode network is as shown in Figure 5. The location of keywords is meaningless on the network, and those with high correlation are located close to one another. In the keyword network, there are links among keyword nodes depending on co-occurrence by calculating cosine similarity, and the links have no directions and weights.

$$
\text { Cosine Similarity }=\frac{\sum_{k=1}^{n} C_{i k} C_{j k}}{\sqrt{\sum_{k=1}^{n} C_{i k}^{2}} \sqrt{\sum_{k=1}^{n} C_{j k}^{2}}}
$$

$\left(C_{i k}=\right.$ number of occurrences of keyword $i, C_{j k}=$ number of occurrences of keyword $\left.j\right)$. 


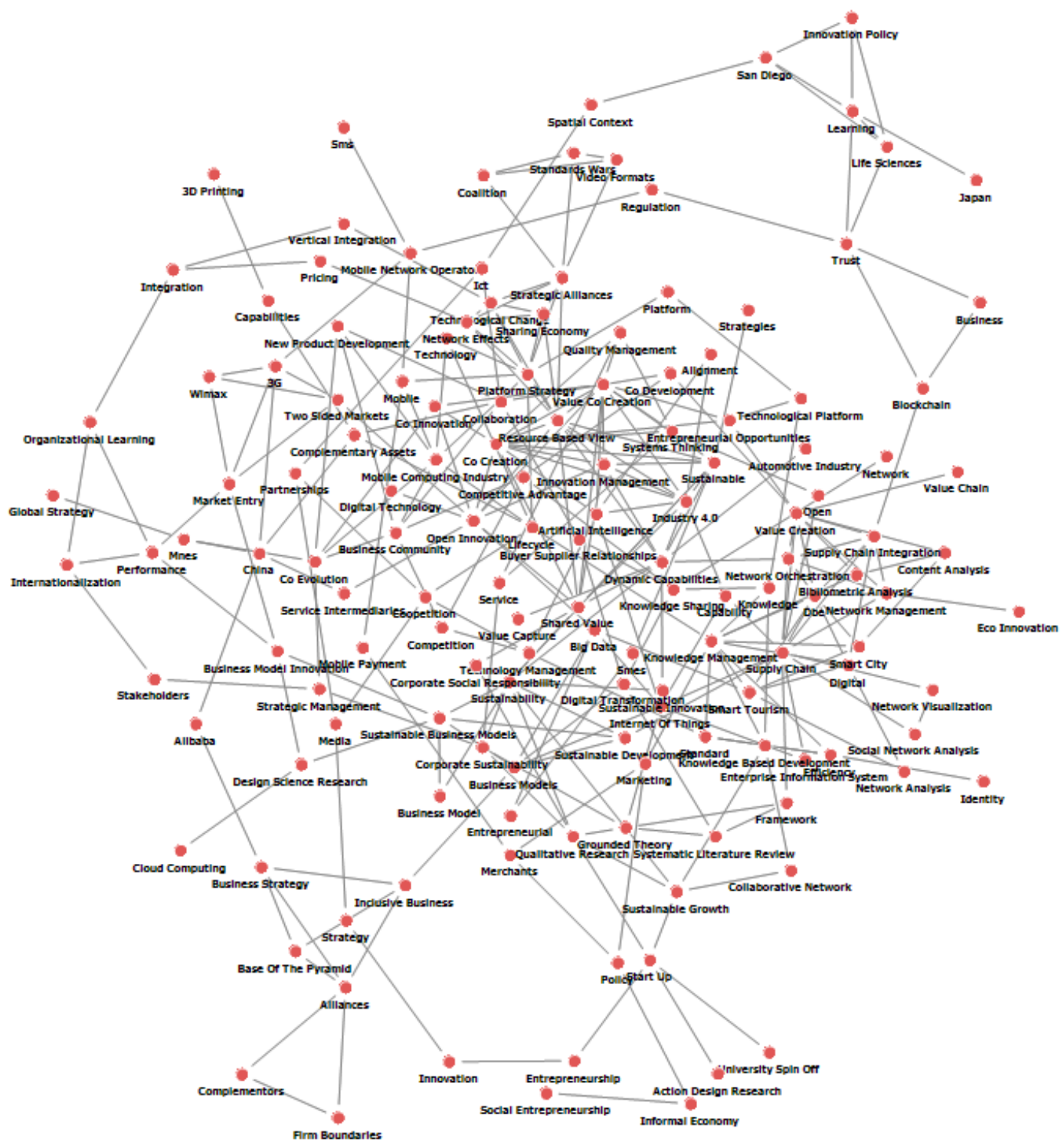

Figure 5. Keyword network.

\subsection{Network Centrality Analysis}

Centrality analysis was conducted after building the keyword network. This study analyzed two types of centralities, the first of which is degree centrality that can be calculated as shown in Equation (2). Degree centrality shows how many direct links one keyword node has with other keyword nodes. Nodes with high degree centrality are linked to many other nodes and thus are analyzed as major nodes in the network. Keywords with high degree centrality in network text analysis are keywords most actively presented by researchers as well as most actively studied subtopics. Table 4 shows the results of degree centrality analysis.

$$
\text { Degree Centrality }=\frac{\sum \text { Weight of Incident Links }}{\text { Number of Nodes }-1}
$$


Table 4. Degree centrality analysis results.

\begin{tabular}{cccc}
\hline Keyword & $\begin{array}{c}\text { Degree } \\
\text { Centrality }\end{array}$ & Keyword & $\begin{array}{c}\text { Degree } \\
\text { Centrality }\end{array}$ \\
\hline Innovation & 0.455882 & Value creation & 0.176471 \\
Sustainability & 0.455882 & Coopetition & 0.161765 \\
Platform & 0.352941 & Value co creation & 0.161765 \\
Business model & 0.323529 & Strategy & 0.147059 \\
Network & 0.294118 & Supply chain & 0.147059 \\
Knowledge & 0.294118 & Service & 0.147059 \\
Digital & 0.279412 & Start up & 0.132353 \\
China & 0.25 & Platform strategy & 0.132353 \\
Entrepreneurship & 0.220588 & Collaboration & 0.132353 \\
Value chain & 0.205882 & Digital transformation & 0.132353 \\
SMEs & 0.205882 & Business models & 0.117647 \\
Open innovation & 0.191176 & Smart tourism & 0.117647 \\
Lifecycle & 0.191176 & Dynamic capabilities & 0.117647 \\
Internet of things & 0.176471 & Industry 4.0 & 0.117647 \\
Case study & 0.176471 & Knowledge sharing & 0.117647 \\
\hline
\end{tabular}

As a result of degree centrality analysis, we discovered that the most actively studied topics on business ecosystems were innovation, sustainability, business model, network, and digital. China was at the top of keywords related to countries, and studies were also actively conducted on small- and medium-sized enterprises (SMEs) and open innovation.

Betweenness centrality was analyzed as the second type of centrality, which can be calculated as shown in Equation (3). Betweenness centrality in a network shows how one node mediates other nodes. When there are nodes $\mathrm{A}, \mathrm{B}, \mathrm{C}$, and $\mathrm{D}$, if $\mathrm{A}$ is linked to $\mathrm{C}$ and $\mathrm{D}$ through $\mathrm{B}, \mathrm{B}$ becomes a node with high betweenness centrality. Keywords with high betweenness centrality in network text analysis are keywords that connect and expand subtopics. Many keywords that are the theories of subareas tend to have high betweenness centrality. Table 5 shows the results of betweenness centrality analysis.

$$
\text { Betweenness Centrality }=\frac{\sum_{j<k} g_{j k}\left(n_{i}\right) / g_{j k}}{\left[\frac{(g-1)(g-2)}{2}\right]}
$$

( $g j k=$ the number of shortest paths that connect nodes $j$ and $k, g j k(n i)=$ the number of paths that pass through node $i$ among the shortest paths that connect nodes $j$ and $k$, $[(g-1)(g-2) / 2]=$ the number of all node pairs not including $n i)$.

Table 5. Betweenness centrality analysis results.

\begin{tabular}{cccc}
\hline Keyword & $\begin{array}{c}\text { Node Betweenness } \\
\text { Centrality }\end{array}$ & Keyword & $\begin{array}{c}\text { Node Betweenness } \\
\text { Centrality }\end{array}$ \\
\hline Sustainability & 0.188014 & Case study & 0.018834 \\
Innovation & 0.184009 & Internet of things & 0.018642 \\
China & 0.088674 & Lifecycle & 0.017606 \\
Platform & 0.078714 & Strategy & 0.01706 \\
Business model & 0.074065 & Value chain & 0.016509 \\
Digital & 0.066884 & Supply chain & 0.0139 \\
Knowledge & 0.065199 & Coopetition & 0.013668 \\
Network & 0.061419 & Open innovation & 0.01346 \\
SMEs & 0.03795 & Value creation & 0.013458 \\
Entrepreneurship & 0.031653 & Service & 0.009756 \\
Business models & 0.024002 & Collaboration & 0.009715 \\
Strategic management & 0.022469 & Business strategy & 0.009713 \\
\hline
\end{tabular}


The results of betweenness centrality analysis were similar to those of degree centrality analysis, and it was discovered that many research articles studied subtopics of business ecosystems by analyzing China's case and SMEs.

\subsection{Cluster Analysis}

Through centrality analysis of the keyword network, actively studied subtopics and expandable topics could be identified in the field of business ecosystems. While major subtopics could be determined by centrality analysis, it is difficult to determine the clusters of each topic. Cluster analysis is conducted to determine which subtopics form a single group in network text analysis. This study conducted a cluster analysis according to Blondel's method [26] and formed five clusters, as shown in Figure 6. This indicates that there are five groups of subtopics in the field of business ecosystems.

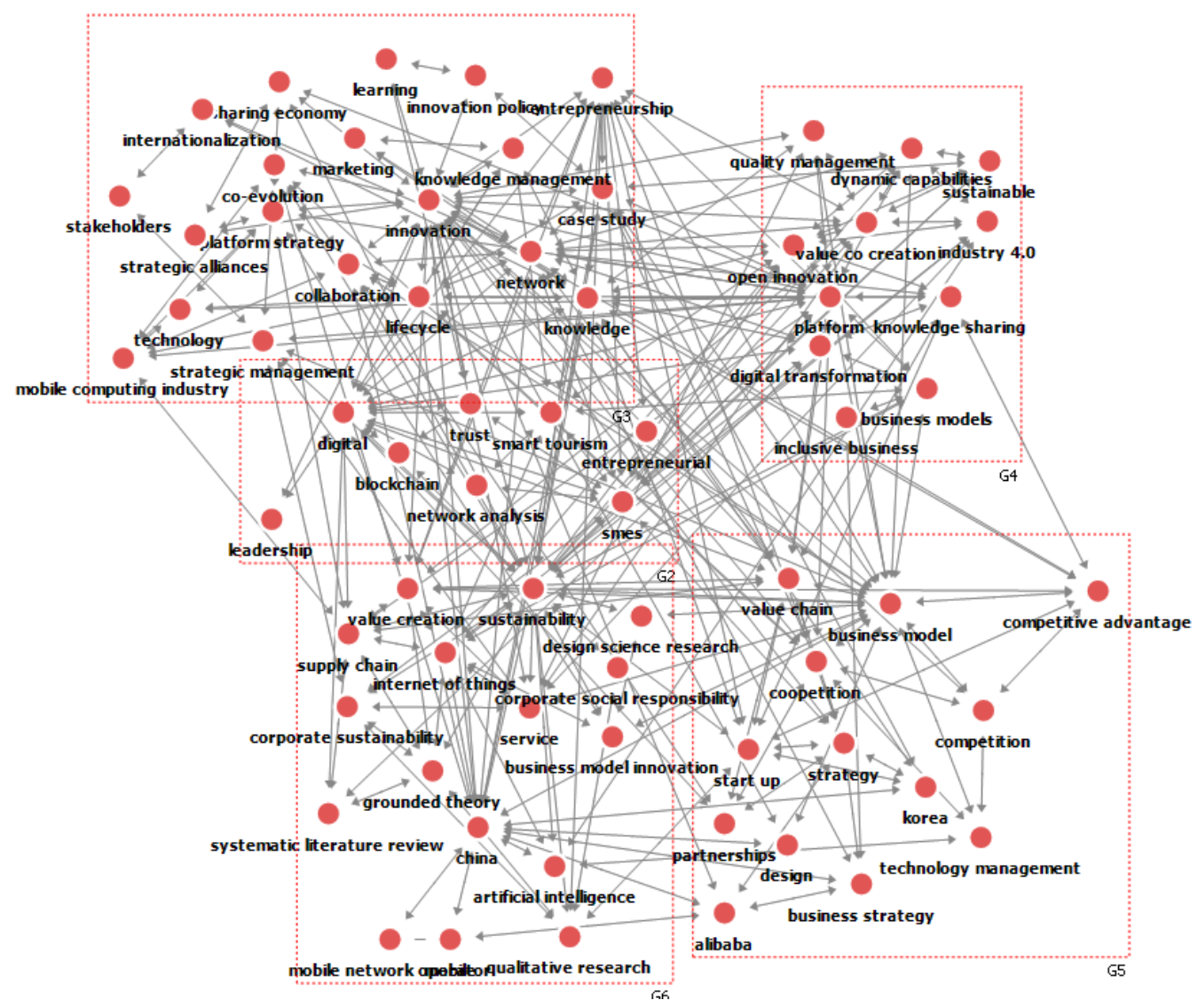

Figure 6. Keyword network clustering.

Table 6 explains the characteristics of main keywords and clusters according to the results of the cluster analysis. The first cluster can be defined as contents related to building business ecosystems to seek organizational innovation beyond knowledge ecosystems for mere technological development. Some of the main studies are summarized as follows. Moore (1993) argues that firms secure competitiveness in a new market by building a business ecosystem and pursue innovation through collaboration. According to Teece [27], firms must have dynamic capabilities to build a business ecosystem and bring innovation to management according to rapid environmental changes, for which they need three capabilities: (1) sense of opportunities and threats, (2) seizing of opportunities, and (3) reconfiguring of the organization's resources to maintain competitiveness. While the purpose of a business ecosystem is to create values focusing on customers, that of a knowledge ecosystem is to co-create new knowledge and technology through collaboration among organizations [28]. Compared to business ecosystems, various organizations are participating in more knowledge ecosystems, showing higher intensity of collaboration [29]. 
Table 6. Main contents of each cluster.

\begin{tabular}{|c|c|c|}
\hline Cluster & Main Keywords & Description \\
\hline 1 & $\begin{array}{l}\text { Entrepreneurship, innovation, } \\
\text { knowledge, co-evolution, learning, } \\
\text { innovation policy }\end{array}$ & $\begin{array}{l}\text { Building business ecosystems for } \\
\text { innovation aiming for customer and } \\
\text { market-oriented value creation beyond } \\
\text { knowledge ecosystems for mere } \\
\text { technological development }\end{array}$ \\
\hline 2 & $\begin{array}{l}\text { Competition, competitive advantage, } \\
\text { value chain, coopetition, partnership }\end{array}$ & $\begin{array}{l}\text { Need to design a new mechanism of } \\
\text { competition, collaboration, and } \\
\text { partnership for business ecosystems }\end{array}$ \\
\hline 3 & $\begin{array}{c}\text { Platform, business models, open } \\
\text { innovation, dynamic capability, value } \\
\text { co-creation }\end{array}$ & $\begin{array}{c}\text { Responding to environmental changes } \\
\text { through platform-based open innovation } \\
\text { and dynamic capability, and establishing } \\
\text { a new business model by creating a } \\
\text { business ecosystem }\end{array}$ \\
\hline 4 & $\begin{array}{l}\text { Sustainability, supply chain, } \\
\text { corporate social responsibility, service }\end{array}$ & $\begin{array}{l}\text { Efforts to seek sustainability of business } \\
\text { ecosystems }\end{array}$ \\
\hline 5 & $\begin{array}{l}\text { Digital, SMEs, leadership, smart } \\
\text { tourism }\end{array}$ & $\begin{array}{l}\text { Digitalizing business ecosystems, coming } \\
\text { up with ways for various organizations } \\
\text { including small- and medium-sized units } \\
\text { to participate in business ecosystems }\end{array}$ \\
\hline
\end{tabular}

The second cluster can be defined as enhancement of competition, collaboration, and partnership beyond value chains among organizations. Value chains and business ecosystems may seem similar, but they are slightly different in terms of meaning. According to Kapoor [30], a value chain takes a micro view that focuses on a single company or product, whereas a business ecosystem takes a macro view that values competitive collaboration and partnership among companies. Therefore, a business ecosystem values cooperative relations with a shared goal beyond the concept of value chains and supply chains [31]. Moreover, it is important to build an integrative relationship along the value chain in order to create a successful business ecosystem [32].

The third cluster includes studies on platform-based open innovation and value co-creation. Platforms are related to network effect, and platform value increases when there are more participants and higher utilization rate, which is why many firms are making efforts to build a business ecosystem for innovation based on platforms [33]. Open innovation emphasizes that it is meaningless for firms to pursue innovation with only internal resources but must exchange resources and co-create values with various external organizations [34]. For open innovation, information, technologies, and resources must be effectively shared by building a business ecosystem [35].

The fourth cluster includes research topics on seeking sustainability by building a business ecosystem. Related studies are as follows. According to Carayannis et al. [36], organizational sustainability is not ensured simply by building a business ecosystem; rather, it can be maintained only when there is strategy sharing and communication, not just within the organization but also among organizations. Moreover, the business ecosystem including the supply chain and value chain must strive for ethical management overall to fulfill social responsibility actually and effectively [37]. In addition, a sustainable business model can be created and operated by defining the new roles of participants in the business ecosystem and designing a collaboration mechanism instead of collaboration in the passive sense for technological development [38].

The fifth cluster is about digitalization and SMEs. According to Tsatsou et al. [39], various digital technologies are changing business ecosystems to operate slightly more organically than before. As business environments are globalized and the complexity of business ecosystems is increasing due to various collaborations among organizations, there are new platforms using digital technologies performing a critical role [40]. Building 
a digital business ecosystem not only incorporates heterogeneous and geographically distant firms into a business ecosystem so that they can produce joint outcomes in a single ecosystem, but also develops new business opportunities and creates a business model more actively and dynamically than before [41]. Digitalization of business ecosystems induces participation of small- and medium-sized units, which had difficulty participating due to various constraints, while also encouraging them to actively perform various roles in the ecosystem [39]. Nonetheless, there are still many constraints for them to actively participate in the business ecosystem through an open innovation platform. Various factors such as product characteristics, appropriacy of partners, regulation, power balance, and contractual agreements must be considered in order for small- and medium-sized units to produce their own results through the business ecosystem.

\section{Conclusions}

To analyze the research trends in the field of business ecosystems, this study searched 340 international articles from Scopus and conducted a network text analysis. Researchers have more and more interest in business ecosystems due to globalization of business environments as well as increase in complexity, and related studies are also constantly increasing. This study extracted keywords from 340 research articles to determine the subtopics and built a one-mode network of keywords, after which it analyzed degree centrality and betweenness centrality. The results showed that the most actively studied subtopic on business ecosystems was innovation. Business ecosystems have a higher level of integration among firms than value chains and supply chains, and they value pursuing shared goals and visions. Therefore, since the focus is on co-creating values among firms and co-evolving abilities, most studies are on innovation. Moreover, it is also beneficial for many competitive participants and stakeholders to participate in a business ecosystem, which is why many studies are conducted from the perspective of platforms and networks. There were many frameworks and theories presented on building a sustainable business ecosystem such as development of a new business model or collaboration mechanism. Furthermore, many studies were conducted to increase the intensity of collaboration among firms and internalize dynamic capabilities with focus on value creation for customers and rapidly changing markets through open innovation, beyond simply knowledge-based collaboration for mere technological development. Recent studies on business ecosystems are focusing on digitalization of business ecosystems using various digital technologies such as the Internet, blockchains, and big data analysis.

A cluster analysis was conducted to identify the groups of subtopics in addition to centrality analysis. The results showed that the subtopics of business ecosystems could be classified into five groups. The first cluster is on building a business ecosystem for innovation beyond just collaboration in technological development, with topics on the basic concepts and methods of building a business ecosystem. The second cluster includes research topics on competition, collaboration, and partnership. Various studies for more collaborative co-creation, co-evolution, and coopetition in a business ecosystem values cooperative relations with shared goals are related to this cluster. The third cluster is on platform-based open innovation, which shows that it is possible to analyze the effects of business ecosystems from the perspective of platforms and networks. The fourth cluster is on sustainability, which includes research topics that constant communication with participants and customers is needed to maintain the business ecosystem, and the ecosystem must be able to fulfill social responsibilities as an ethical standard. The final cluster is on digitalization of business ecosystems, emphasizing that more firms can be incorporated into the ecosystem through digitalization and that new opportunities can be seized by quickly and transparently sharing information and developing new business models.

\section{Implications and Limitations}

This study provides the following implications. First, the overall research trends in business ecosystems are quantified and presented through network text analysis. Previous 
studies are not analyzed by the subjectivity of researchers, but unstructured text data are quantified and analyzed, thereby more objectively explaining the research trends. This is expected to help researchers in attempting to conduct systematic literature review on business ecosystems. Second, this study provides ideas for future research topics by summarizing and organizing subtopics in the field of business ecosystems. While studies on business ecosystems thus far have been mostly from the perspective of platforms and networks or related to sustainability with focus on innovation, now studies must be actively conducted on Industry 4.0 and digital transformation. Currently, firms are hyperconnected using smart information technology and data analytic techniques, and analysis and application technologies have become hyperintelligent. Many firms are sharing information in real time for a collaborative ecosystem and making various efforts to deal with management risks. In the circumstances, it is necessary to shed new light on the concept of business ecosystems. Moreover, various studies can also be conducted in association with the new business environment of the new normal era derived from the recent COVID-19 pandemic. Thus, it is critical to investigate changes in the business models, platforms, and innovations strategies of business ecosystem in the digital and COVID-19 era. Third, this study summarizes and provides methodologies for research trend analysis using network text analysis. With various literature reviews recently conducted on the basis of network analysis, the method of network text analysis presented in this study can be used to analyze the research trends in various fields.

Despite many implications, this study has the following limitations. First, since only the database of Scopus was used to search the articles, some of the influential articles on business ecosystems that are not indexed on Scopus might have been omitted. Further research must select research articles by adding other academic search databases such as Google Scholar. Second, PageRank, co-citation network, and author network analysis can be used to analyze not only the trends in research topics but also major researchers and researcher groups as well as influential articles, but they were not used in this study. Additional analysis must be conducted in further studies conducting research trend analysis.

Author Contributions: Conceptualization, M.M.S. and J.S.R.; methodology, M.M.S. and J.S.R.; software, J.S.R.; validation, M.M.S. and J.S.R.; formal analysis, M.M.S., S.J. and J.S.R. All authors have read and agreed to the published version of the manuscript.

Funding: This research received no external funding.

Institutional Review Board Statement: Not applicable.

Informed Consent Statement: Not applicable.

Data Availability Statement: No new data were created or analyzed in this study. Data sharing is not applicable to this article.

Acknowledgments: Authors of the current study MS, SJ, and JR are grateful for the anonymous peer reviewers and the editors for their critical comments, which helped to significantly improve the quality of this paper.

Conflicts of Interest: The authors declare no conflict of interest.

\section{References}

1. Muegge, S. Platforms, Communities, and Business Ecosystems: Lessons Learned about Technology Entrepreneurship in an Interconnected World. Technol. Innov. Manag. Rev. 2013, 3, 5-15. [CrossRef]

2. Moore, J.F. Predators and Prey: A New Ecology of Competition. Harv. Bus. Rev. 1993, 71, 75-86. [PubMed]

3. Anggraeni, E.; Den Hartigh, E.; Zegveld, M. Business Ecosystem as a Perspective for Studying the Relations between Firms and their Business Networks. In Proceedings of the ECCON 2007 Annual Meeting, Basel, Switzerland, 3-7 September 2017; pp. 1-28.

4. Richardson, J.E. The Business Model: An Integrative Framework for Strategy Execution. 2005. Available online: https://papers. ssrn.com/sol3/papers.cfm?abstract_id=932998 (accessed on 25 September 2021).

5. Teece, D.J. Business Models, Business Strategy and Innovation. Long Range Plan. 2010, 43, 172-194. [CrossRef]

6. D'Souza, A.; Wortmann, H.; Huitema, G.; Velthuijsen, H. A Business Model Design Framework for Viability; A Business Ecosystem Approach. J. Bus. Models 2015, 3, 1-29. 
7. Chesbrough, H. Business Model Innovation: Opportunities and Barriers. Long Range Plan. 2010, 43, 354-363. [CrossRef]

8. Peltoniemi, M.; Vuori, E. Business Ecosystem as the New Approach to Complex Adaptive Business Environments. Proc. eBusiness Res. Forum 2004, 2, 267-281.

9. Corallo, A.; Protopapa, S. Business Networks and Ecosystems: Rethinking the Biological Metaphor. Digit. Bus. Ecosyst. 2007, $6064,1-6$.

10. Iansiti, M.; Levien, R. The Keystone Advantage: What the New Dynamics of Business Ecosystems Mean for Strategy, Innovation, and Sustainability; Harvard Business Press: Boston, MA, USA, 2004.

11. Jacobides, M.G.; Cennamo, C.; Gawer, A. Towards a Theory of Ecosystems. Strateg. Manag. J. 2018, 39, 2255-2276. [CrossRef]

12. Cantwell, J.A. Blurred Boundaries between Firms, and New Boundaries within (Large Multinational) Firms: The Impact of Decentralized Networks for Innovation. Seoul J. Econ. 2013, 26, 1-32.

13. Alves, J.; Marques, M.J.; Saur, I.; Marques, P. Creativity and Innovation through Multidisciplinary and Multisectoral Cooperation. Creat. Innov. Manag. 2007, 16, 27-34. [CrossRef]

14. Iansiti, M.; Levien, R. Strategy as Ecology. Harv. Bus. Rev. 2004, 82, 68-78.

15. Mooer, J.F. The Death of Competition: Leadership and Strategy in the Age of Business Ecosystem; Harper Business: New York, NY, USA, 1996.

16. Den Hartigh, E.; Van Asseldonk, T. Business Ecosystems: A Research Framework for Investigating the Relation between Network Structure, Firm Strategy, and the Pattern of Innovation Diffusion. In Proceedings of the ECCON 2004 Annual Meeting: Co-Jumping on a Trampoline, Driebergen, The Netherlands, 22-23 October 2004.

17. Quaadgras, A. Who Joins the Platform? In the Case of the RFID Business Ecosystem. In Proceedings of the 38th Annual Hawaii International Conference on System Sciences, Hilton Waikoloa Village, Waikoloa Village, HI, USA, 3-6 January 2018 ; p. 269b.

18. Li, Y. The technological roadmap of Cisco's business ecosystem. In Software Ecosystems; Edward Elgar Publishing: Cheltenham, UK, 2013.

19. Tsujimoto, M.; Kajikawa, Y.; Tomita, J.; Matsumoto, Y. A Review of the Ecosystem concept-Towards Coherent Ecosystem Design. Technol. Forecast. Soc. Chang. 2018, 136, 49-58. [CrossRef]

20. Ritter, T.; Gemünden, H.G. Network Competence: Its Impact on Innovation Success and its Antecedents. J. Bus. Res. 2003, 56, 745-755. [CrossRef]

21. Ismail, M.H.; Khater, M.; Zaki, M. Digital Business Transformation and Strategy: What do we Know so Far. Camb. Serv. Alliance 2017, 10, 1-35.

22. Rha, J.S. Trends of Research on Supply Chain Resilience: A Systematic Review using Network Analysis. Sustainability 2020, 12, 4343. [CrossRef]

23. Fahimnia, B.; Tang, C.S.; Davarzani, H.; Sarkis, J. Quantitative Models for Managing Supply Chain Risks: A Review. Eur. J. Oper. Res. 2015, 247, 1-15. [CrossRef]

24. Fahimnia, B.; Sarkis, J.; Davarzani, H. Green Supply Chain Management: A Review and Bibliometric Analysis. Int. J. Prod. Econ. 2015, 162, 101-114. [CrossRef]

25. Yu, S.; Rha, J. Research Trends in Accounting Fraud using Network Analysis. Sustainability 2021, 13, 5579. [CrossRef]

26. Blondel, V.D.; Guillaume, J.; Lambiotte, R.; Lefebvre, E. Fast Unfolding of Communities in Large Networks. J. Stat. Mech. Theory Exp. 2008, 2008, P10008. [CrossRef]

27. Teece, D.J. Explicating Dynamic Capabilities: The Nature and Microfoundations of (Sustainable) Enterprise Performance. Strateg. Manag. J. 2007, 28, 1319-1350. [CrossRef]

28. Romero, D.; Molina, A. Collaborative Networked Organisations and Customer Communities: Value Co-Creation and CoInnovation in the Networking Era. Prod. Plan. Control 2011, 22, 447-472. [CrossRef]

29. Clarysse, B.; Wright, M.; Bruneel, J.; Mahajan, A. Creating Value in Ecosystems: Crossing the Chasm between Knowledge and Business Ecosystems. Res. Policy 2014, 43, 1164-1176. [CrossRef]

30. Kapoor, R. Ecosystems: Broadening the Locus of Value Creation. J. Organ. Des. 2018, 7, 1-16. [CrossRef]

31. Weiller, C.; Shang, T.; Neely, A.; Shi, Y. Competing and Co-existing Business Models for EV: Lessons from International Case Studies. Int. J. Automot. Technol. Manag. 2015, 15, 126-148. [CrossRef]

32. Gomes, J.F.; Iivari, M.; Pikkarainen, M.; Ahokangas, P. Business Models as Enablers of Ecosystemic Interaction: A Dynamic Capability Perspective. Int. J. Soc. Ecol. Sustain. Dev. (IJSESD) 2018, 9, 1-13. [CrossRef]

33. Gawer, A.; Cusumano, M.A. Industry Platforms and Ecosystem Innovation. J. Prod. Innov. Manag. 2014, 31, 417-433. [CrossRef]

34. Parker, G.; Van Alstyne, M. Innovation, Openness, and Platform Control. Manag. Sci. 2018, 64, 3015-3032. [CrossRef]

35. Gretzel, U.; Sigala, M.; Xiang, Z.; Koo, C. Smart Tourism: Foundations and Developments. Electron. Mark. 2015, 25, 179-188. [CrossRef]

36. Carayannis, E.G.; Sindakis, S.; Walter, C. Business Model Innovation as Lever of Organizational Sustainability. J. Technol. Transf. 2015, 40, 85-104. [CrossRef]

37. Tencati, A.; Zsolnai, L. The Collaborative Enterprise. J. Bus. Ethics 2009, 85, 367-376. [CrossRef]

38. Hellström, M.; Tsvetkova, A.; Gustafsson, M.; Wikström, K. Collaboration Mechanisms for Business Models in Distributed Energy Ecosystems. J. Clean. Prod. 2015, 102, 226-236. [CrossRef]

39. Tsatsou, P.; Elaluf-Calderwood, S.; Liebenau, J. Towards a Taxonomy for Regulatory Issues in a Digital Business Ecosystem in the EU. J. Inf. Technol. 2010, 25, 288-307. [CrossRef] 
40. Del Chiappa, G.; Baggio, R. Knowledge Transfer in Smart Tourism Destinations: Analyzing the Effects of a Network Structure. J. Destin. Mark. Manag. 2015, 4, 145-150. [CrossRef]

41. Senyo, P.K.; Liu, K.; Effah, J. Digital Business Ecosystem: Literature Review and a Framework for Future Research. Int. J. Inf. Manag. 2019, 47, 52-64. [CrossRef] 